Research Article

\title{
Process Control of Ball Mill Based on MPC-DO
}

\author{
Xisong Chen, ${ }^{1}$ Jiawei Yang, ${ }^{2,3,4,5}$ Zhijie Zhong, $^{1}$ and Junyong Zhai $\mathbb{D}^{1}$ \\ ${ }^{1}$ School of Automation, Southeast University, Nanjing 210096, China \\ ${ }^{2}$ State Key Laboratory of Process Automation in Mining \& Metallurgy, Beijing 102628, China \\ ${ }^{3}$ Beijing Key Laboratory of Process Automation in Mining \& Metallurgy, Beijing 102628, China \\ ${ }^{4}$ Beijing General Research Institute of Mining and Metallurgy, Beijing 100160, China \\ ${ }^{5}$ Northeastern University, Shenyang 110819, China
}

Correspondence should be addressed to Junyong Zhai; jyzhai@seu.edu.cn

Received 2 April 2021; Revised 9 June 2021; Accepted 3 July 2021; Published 26 July 2021

Academic Editor: Omar-Jacobo Santos

Copyright $\odot 2021$ Xisong Chen et al. This is an open access article distributed under the Creative Commons Attribution License, which permits unrestricted use, distribution, and reproduction in any medium, provided the original work is properly cited.

\begin{abstract}
The grinding process of the ball mill is an essential operation in metallurgical concentration plants. Generally, the model of the process is established as a multivariable system characterized with strong coupling and time delay. In previous research, a twoinput-two-output model was applied to describe the system, in which some key indicators of the process were ignored. To this end, a three-input-three-output system is proposed to improve the model accuracy. Moreover, some practical and effective control strategies have been studied. The common control methods, including model predictive control (MPC), disturbance observer (DO), and so on, show poor performance when strong external and internal disturbances exist. In this paper, a composite control strategy based on MPC-DO is put forward to realize the control of the three-input-three-output ball mill system. The disturbances of the system consist of external disturbances including fluctuation of ore hardness and internal disturbances including model mismatches and strong couplings. The proposed MPC-DO controller includes a feedback control component based on MPC and a feed-forward compensation component based on DO. The simulation results indicate that the composite control scheme based on MPC-DO has good performance of tracking and anti-interference in process control of the ball mill.
\end{abstract}

\section{Introduction}

Grinding and classification process (GCP) is a key process in the beneficiation production process of the metallurgical industry. In general, the beneficiation process includes crushing (medium crushing and fine crushing), gravity separation, magnetic separation, GCP, flotation separation, concentration, and filtration.

Beneficiation refers to the removal of harmful elements contained in the raw ore to enrich the useful minerals and separate the various useful minerals from each other. The grade (percentage of useful mineral content) from underground mine is generally low and unable to be smelted directly. Therefore, ore beneficiation is required to remove most of the gangue and harmful components to obtain a high-grade concentrate. For example, if the grade of iron is increased by $1 \%$, the yield of iron from blast furnace can be increased by $2.5 \%$, and the coke ratio can be reduced by
$1.5 \%$. In addition, if the iron concentrate contains high content of sulfur and phosphorus, it will be harmful to the smelting process. So, the content of sulfur and phosphorus should be reduced during the beneficiation process. Obviously, beneficiation is of great significance to the development of mining industry and the full utilization of mineral symbiosis resources. GCP is the continuation of the crushing and separation process. The purpose of GCP is to make most of the useful components in the ore reach the monomer separation (micron level) through grinding and to avoid the phenomenon of overcrushing. After GCP, the particle size can meet the requirements of sorting operations (e.g., magnetic separation and magnetic flotation), creating conditions for the effective recovery of useful components in the ore $[1-4]$.

Ball mill is a typical grinding equipment in the metallurgical concentration plants. Among all the operation elements in GCP, the grinding process of the ball mill is the 
most significant one, which consumes the most electricity of concentration plants. Product particle size of the ball mill affects the recovery rate of useful components in ore and tail disposal afterwards. Generally, the purpose of GCP is to achieve efficient control of product particle size. However, undesirable features (i.e., strong couplings between variables, disturbances, complicated dynamic characteristics, and time delays) always bring challenges to researchers [5]. In recent years, in addition to the traditional PID controller [6], a lot of advanced control strategies, such as MPC [7-12], adaptive control [11, 13, 14], neural network control [15], robust control [16,17], optimal control [18], supervisory control [3], and expert control [19], have been put forward. MPC is one of the most popular approaches in the field of GCP. Since the model predictive heuristic control algorithm (MPHC) [20] was proposed in 1978, MPC has achieved great development and has derived a series of algorithms such as model algorithmic control (MAC) [21]. MPC is not only a purely theoretical product but also a practical control method.

The advantages of MPC are listed as follows [11]: (1) perfect capability of dealing with MIMO systems, (2) performing decoupling and handling time delays, and (3) simplicity of modeling.

In GCP, disturbance has a great impact on the performance of ball mill grinding circuits. Product particle size, circulating load, and mill solid concentration are always sensitive to different types of disturbances. The disturbances are separated into external disturbances and internal disturbances [22]. External disturbances contain variations of the properties of raw ore (e.g., hardness). Strong external disturbances may lead to continuous fluctuation of product particle size, circulating load, and mill solid concentration. Moreover, internal disturbances include model mismatches, unmodeled dynamics, and couplings. Internal disturbances are likely to contribute to bad dynamic performances and even unstable state of the whole system.

It must be noted that the control strategies mentioned above show some limited abilities in GCP of the ball mill in the presence of strong disturbances as they are unable to handle disturbances directly through the design of controller. Although the controllers can resist disturbances slowly by feedback controller, the control schemes become inefficient when coming across strong disturbances. For the sake of improving the anti-interference performance of the ball mill, a feed-forward compensation component is introduced into controller design as a supplement to the traditional feedback controller. However, it is difficult to measure the disturbances directly through instruments. One possible solution is to research the technology of disturbance estimation. DO is an efficient way to estimate disturbances. DO was firstly raised by Ohishi et al. [23] in motion control. Control schemes based on DO have been promptly applied to other fields, such as robots $[24,25]$, hard disk drive (HDD) $[26,27]$, and so on. At present, DO has a wide range of applications. Pan [28] proposes a combination of adaptive robust control (ARC) and a novel terminal sliding-modebased nonlinear disturbance observer (TSDO) to achieve robust output tracking for the saturated uncertain nonlinear systems, where the modeling inaccuracy and disturbance are integrated as a lumped disturbance. The reasons of successful application of DO lie in the following three advantages [11]: (1) the design of DO does not need to depend on accurate modeling of disturbance, (2) DO is able to be applied to deal with unmeasurable disturbance, and (3) DO does not have to distinguish between external and internal disturbances. As DO achieves complete suppression of disturbances, it has been used extensively in the design of feed-forward compensation.

For a long time, GCP control has been the research focus of mineral processing at home and abroad. PID control based on two-input-two-output model [22] is widely used in GCP. However, it has a problem that the accuracy of the model is not high enough. The purpose of this article is to design a controller to achieve effective control of GCP. In this paper, different from the traditional two-input-twooutput model of the ball mill grinding process, a three-inputthree-output system considering the influence of three factors (i.e., fresh ore feed, dilution water, and mill feed water) is put forward to improve the accuracy of modeling. Furthermore, a compound control strategy for process control of the ball mill is proposed to describe the grinding process precisely where disturbances exist. It consists of two types of controllers - a feedback regulation component based on MPC and a feed-forward compensation component based on DO. In comparison to other schemes, the proposed strategy considers both types of disturbances. As the MPC-DO controller inherits advantages of both MPC and DO, it shows great performance in the following three aspects: (1) good decoupling property, (2) ability to deal with processes with time delay, and (3) capability in dealing with strong disturbances.

The structure of the paper is listed as follows. A brief introduction to the research background is given in Section 1. In Section 2, the characteristics of grinding process are demonstrated. In Section 3, basic introductions of MPC and DO are firstly illustrated, and then a composite MPC-DO controller is introduced to the process control of grinding. In Section 4, a three-inputthree-output system is proposed, and the proposed MPCDO controller is applied to the model. Simulation results verify the performance of the controller. Finally, conclusions are drawn in Section 5.

\section{Grinding Process of Ball Mill}

In this section, the characteristics of the ball mill grinding process are demonstrated. Then, the controlled variables and the manipulated variables are imposed, respectively. Finally, the relationships among all the variables and disturbances are introduced briefly.

GCP is a widespread process applied in metallurgical concentration plants for size reduction. Its role is releasing valuable components from raw ore $[22,29]$. Ball mill is the typical equipment widely employed in GCP. The flow diagram of the ball mill system is illustrated in Figure 1, including the ball mill, pump sump, hydro-cyclones, and vibratory conveyor. 


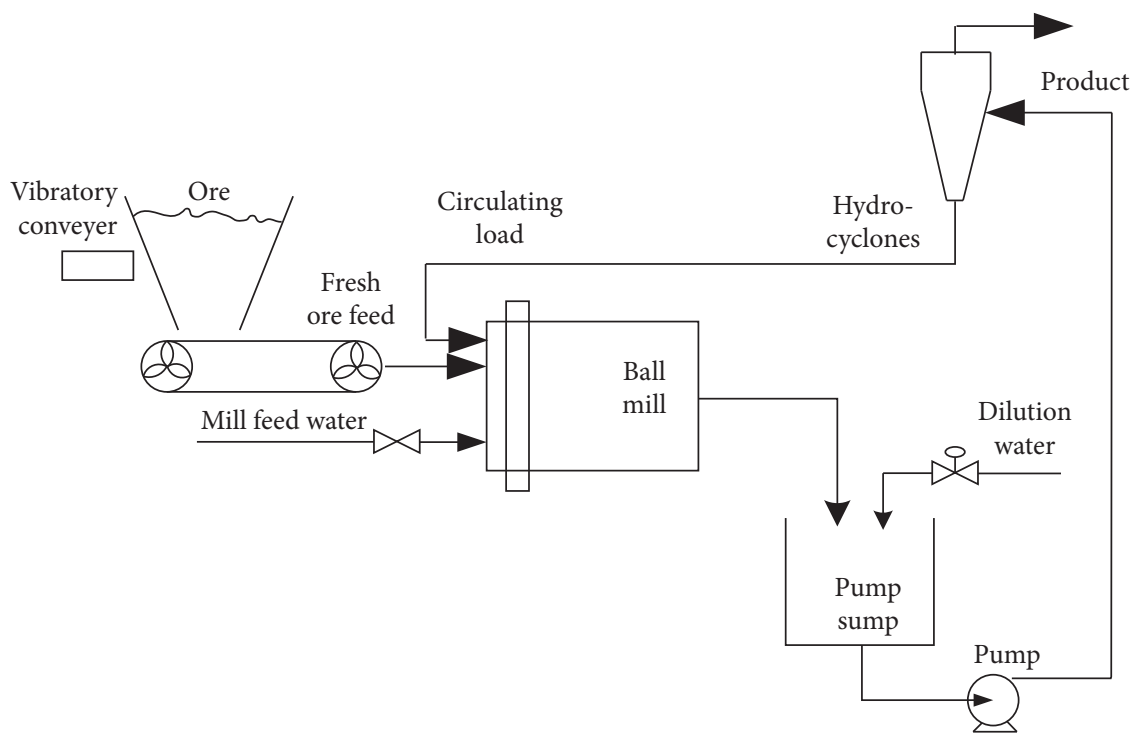

Figure 1: Flow diagram of the ball mill grinding process.

The system dynamics are described as follows. During the grinding process, the raw ore is firstly sent into the ball mill mixed with water. After that, the fresh raw ore is crushed to finer sizes by tumbling. The slurry with fine particles is then transferred to the pump sump. The dilution action adds water to the pump sump. Then, the slurry is pumped into the hydro-cyclones, which are used for further classification after dilution. After all the operations, the slurry is divided into an overflow stream comprising the substandard particles and an underflow stream comprising the substandard particles for recycling [22]. The fine particles, which meet the standard requirement of particle size, are the target product. The substandard particles are usually recycled back to the production line for regrinding and are selected as circulating load [3].

Product particle size $y_{1}(\%)$ is regarded as the most significant controlled variable in the ball mill system. Raw ore has to be crushed to the specific size so that the fine particles are exposed in preparation for effective recovery during the subsequent technological processes. Besides, circulating load $y_{2}(t / h)$ is one of the controlled variables as it describes the amount of ore which is recycled to the production line. Moreover, mill solid concentration $y_{3}(\%)$ is another controlled variable as the solid concentration must be controlled within a reasonable range. Generally, the scope of product particle size is $65 \%-75 \%$, the scope of circulating load is $120 \mathrm{t} / \mathrm{h}-180 \mathrm{t} / \mathrm{h}$, and the scope of mill solid concentration is $40 \%$ solids $\sim 60 \%$ solids. The upper limit of product particle size is set to prevent the excessively high particle size from causing the mill to be overloaded or the pipeline to be blocked. The upper limit of circulating load is set to prevent blockage of the slurry pipeline. The upper limit of mill solid concentration is set to ensure the relatively stable production volume. The lower limits of the controlled variables are set for economic considerations.

During the grinding process, strong external disturbances may contribute to persistent fluctuations of product particle size in some cases. In this paper, we supplement the existing research results by rebuilding the model. The control objective is to realize the stability of controlled variables $y_{1}, y_{2}$, and $y_{3}$. The controlled variables can be adjusted by operating the manipulated variables, which are fresh ore feed rate $u_{1}$, dilution water feed rate $u_{2}$, and mill feed water feed rate $u_{3}$, respectively. The relationships among all the variables and disturbances in the ball mill system are introduced briefly in Figure 2.

These three controlled variables and three manipulated variables are completely determined by process analysis. The establishment of the model is based on process testing. Specifically, a step disturbance is applied to one of the manipulated variables near the equilibrium point in turn to observe the dynamic changes of the three controlled variables. By observing the dynamic changes, the change curves can be obtained, and the transfer function models can be obtained by curve fitting. The transfer function consists of a minimum-phase part and a time delay part.

\section{Design of Controller}

In this section, a compound strategy is put forward to deal with problems mentioned above in the ball mill grinding process. Principles of MPC and DO are firstly illustrated. After that, the MPC-DO controller is designed to realize the control objective.

3.1. Basic Introduction of MPC and DO. MPC algorithm has been applied extensively since it was proposed in 1980. In a system with $m$ manipulated variables and $p$ controlled variables, the quadratic performance objective function of the unconstrained MPC algorithm is listed as follows $[11,30]$ : 


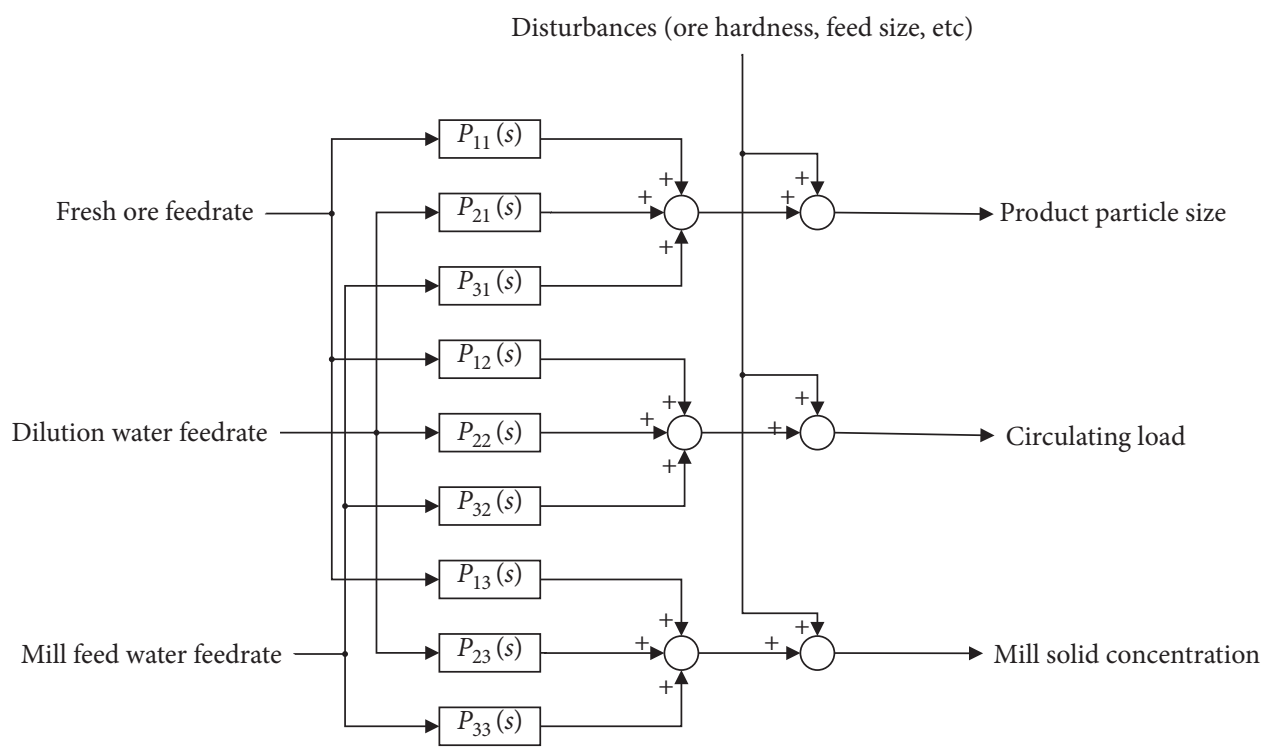

FIGURE 2: The relationships among the variables and disturbances.

$$
\begin{aligned}
\min _{\triangle u_{M}} J(k)= & {\left[y_{r}(k)-\tilde{y}_{P}(k)\right]^{T} \mathbf{Q}\left[y_{r}(k)-\tilde{y}_{P}(k)\right] } \\
& +\left[\Delta u_{M}(k)\right]^{T} \mathbf{R}\left[\Delta u_{M}(k)\right],
\end{aligned}
$$

where $y_{r}(k)$ represents the setpoint of $p$ controlled variables within $P$ sampling intervals in the future, $\Delta u_{M}(k)$ stands for variations of $m$ manipulated variables within $M$ sampling intervals in the future, $P$ and $M$ denote the prediction horizon and control horizon, respectively, and $\mathbf{Q}(P p \times P p)$ and $\mathbf{R}(M m \times M m)$ are the error weighting matrix and input weighting matrix, respectively. The model prediction values of outputs are represented as

$$
\widetilde{\mathbf{y}}_{N}(k)=\tilde{\mathbf{y}}_{0}(k)+\mathbf{A} \Delta u_{M}(k)
$$

where $\widetilde{\mathbf{y}}_{N}(k)$ represents the model prediction vector and $\tilde{\mathbf{y}}_{0}(k)$ represents the initial predicted output vector without controller. A is a multivariable MPC dynamic matrix from the coefficients of unit step response. Because of the influence of measurement noise, the predicted outputs are usually imprecise and ought to be corrected by the real outputs. Construct $\mathbf{e}(k+1)$ as the vector of predicted errors for the $p$ controlled variables:

$$
\begin{aligned}
\mathbf{e}(k+1) & =\left[\mathbf{e}_{1}(k+1), \ldots, \mathbf{e}_{p}(k+1)\right]^{T} \\
& =\left[y_{1}(k+1)-\widetilde{y}_{1,1}(k+1 \mid k), \ldots, y_{p}(k+1)-\widetilde{y}_{p, 1}(k+1 \mid k)\right]^{T},
\end{aligned}
$$

where $\tilde{y}_{i, 1}(k+1 \mid k)(i=1, \ldots, p)$ is the model prediction of $p$ controlled variables at the $(k+1)$ th sampling interval. Therefore, the predicted outputs after correction can be listed as

$$
\widetilde{\mathbf{y}}_{p}(k)=\widetilde{\mathbf{y}}_{N}(k)+\mathbf{H e}(k+1)
$$

where $\tilde{\mathbf{y}}_{p}(k)$ represents the predictive output after correction and $\mathbf{H}$ represents the corrected coefficient matrix. It can be solved from (1) that

$$
\Delta u_{M}(k)=\left(\mathbf{A}^{T} \mathbf{Q A}+\mathbf{R}\right)^{-1} \mathbf{A} \mathbf{Q}\left[y_{r}(k)-\tilde{y}_{p}(k)\right] .
$$

Generally, dynamic decoupling requires accurate modeling of process and brings challenges to industrial production. In comparison, static decoupling has more applications. However, static decoupling degrades the performance of control as it does not take the dynamic characteristics of process into consideration. MPC shows superb performance of decoupling. But it shows some limitations when strong disturbances exist. Therefore, DO is needed to compensate for disturbances.

In the field of motion control, DO has achieved many successful applications. DO can achieve better tracking and estimation of disturbance factors (external disturbance, model mismatching, and so on) that affect the system. This type of observer does not rely on precise disturbance analysis modeling and can organically combine observation results with controller design. Therefore, the state coupling between the channels that affects the performance of the system is regarded as the disturbance of each channel, and the corresponding disturbance observer for each channel is designed to suppress the internal disturbance and the external disturbance of the channel. In this paper, the technology of DO is introduced into the process control field. 
Combined with the design of feedback controller based on MPC, a new compound control scheme is put forward.

3.2. Controller Based on MPC-DO. MPC, as the feedback regulation part of the controller, has been well integrated by the Model Predictive Toolbox of Simulink. As a result, the focus of the design is DO.

The structure of conventional DO is shown in Figure 3 [31]. In Figure 3(a), signals $C(s), U(s), D_{\text {ex }}(s), N(s)$, and $Y(s)$ are the command of the controller, the manipulated variable, the external disturbance, the measurement noise, and the controlled variable, respectively. $Q(s)$ is the low-pass filter. Signals $\widehat{D}(s)$ and $\widehat{D}_{f}(s)$ are the estimates of the lumped disturbances before and after filtering. $P(s)$ is the real object to be controlled, while $G(s)$ is the model of the object. The transfer function has the following form:

$$
Y(s)=G_{c}(s) C(s)+G_{d}(s) D_{\mathrm{ex}}(s)+G_{n}(s) N(s),
$$

where

$$
\begin{aligned}
G_{c}(s) & =\frac{P(s) G(s)}{G(s)+(P(s)-G(s)) Q(s)}, \\
G_{d}(s) & =\frac{P(s) G(s)(1-Q(s))}{G(s)+(P(s)-G(s)) Q(s)}, \\
G_{n}(s) & =\frac{P(s) Q(s)}{G(s)+(P(s)-G(s)) Q(s)} .
\end{aligned}
$$

The design of DO is chiefly dependent on low-pass filter $Q(s)$. Furthermore, as the anti-disturbance performance of the system is determined by time constants of $Q(s)$, it is necessary to choose suitable time constants.

Case 1. If $Q(s) \longrightarrow 1$, then

$$
\begin{aligned}
& G_{c}(s) \longrightarrow G(s), \\
& G_{d}(s) \longrightarrow 0, \\
& G_{n}(s) \longrightarrow 1 .
\end{aligned}
$$

Under this circumstance, the dynamic properties of the system resemble those of $G(s)$.

Case 2. If $Q(s) \longrightarrow 0$, it can be deduced that

$$
\begin{aligned}
& G_{c}(s) \longrightarrow P(s), \\
& G_{d}(s) \longrightarrow P(s), \\
& G_{n}(s) \longrightarrow 0 .
\end{aligned}
$$

Under the circumstance, the system is approximately open-loop. As a result, measurement noise is removed.

In low-frequency domain, $Q(s)$ is approximately equal to 1 , ensuring the estimated value of the lumped disturbance approach to the real value, which means the feed-forward compensation component can attenuate the influences of disturbances. Furthermore, in high-frequency domain, $Q(s)$ approaches 0 . It guarantees that the system is approximately open-loop and the high-frequency measurement noise can be removed by filtration.

In most cases, $G^{-1}(s)$ is physically unrealizable. In consideration of the internal disturbance $D_{m}(s)$ resulting from model mismatches, an equivalent conventional DO is illustrated in Figure 3(b). In order to ensure the realizability, $Q(s) G^{-1}(s)$ must be proper. The relative degree of $Q(s)$ ought to be no less than that of $G(s)$.

Define $D(s)$ as the lumped disturbances. It is obvious that $D(s)$ include external disturbance $D_{\text {ex }}(s)$ and internal disturbance $D_{m}(s)$ resulting from model mismatches:

$$
D(s)=D_{\text {ex }}(s)+D_{m}(s),
$$

where $D_{m}(s)=\left[P(s) G^{-1}(s)-1\right]\left(U(s)+D_{\text {ex }}(s)\right)$.

$\mathrm{DO}$ is able to deal with both types of disturbances without distinguishing. Therefore, the internal disturbance $D_{m}(s)$ aroused by model mismatching can be compensated.

In the process of grinding, as the inverse function of time delay part is physically unrealizable, conventional DO tends to be unavailable. Here modified disturbance observer [32] considering the time delay parts is used to deal with the problems mentioned above.

Take the two-input-two-output model for example:

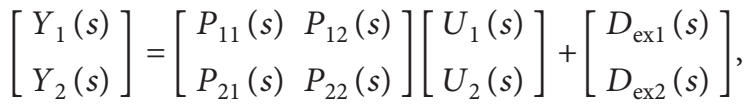

where $Y_{i}(s)(i=1,2)$ are the controlled variables, $U_{i}(s)$ $(i=1,2)$ are the manipulated variables, $P_{i j}(s)(i=1,2 ; j=$ $1,2)$ are the models of process channels with $P_{i j}(s)=$ $p_{i j}(s) e^{-\tau_{i j} s}(i=1,2 ; j=1,2), \quad p_{i j}(s)(i=1,2 ; j=1,2)$ are the minimum-phase parts of $P_{i j}(s)$ and $e^{-\tau_{i j} s}(i=1,2 ; j=1,2)$ are the time delay parts of $P_{i j}(s), D_{\text {ex }}(s)$ are the external disturbances with $D_{\text {ex } i}(s)=H_{i}(s) D_{\text {ex }}(s)(i=1,2), D_{\text {ex } i}(s)$ $(i=1,2)$ are the effects of $D_{\mathrm{ex}}(s)$ on $Y_{i}(s), D_{\mathrm{ex} i}(s)=$ $H_{i}(s) D_{\mathrm{ex}}(s)(i=1,2)$, and $H_{i}(s)(i=1,2)$ are the disturbance models.

The structure of modified DO for $u_{1}-y_{1}$ loop is shown in Figure 4. The structure of $u_{2}-y_{2}$ loop is similar to that of $u_{1}-y_{1}$ loop. Obviously, the model $P_{11}(s)$ is divided into two parts-a minimum-phase part $p_{11}$ and a time delay part $e^{-\tau_{11}} s$ :

$$
P_{11}(s)=p_{11}(s) e^{-\tau_{11} s} .
$$

The nominal model $G_{11}(s)$ is

$$
G_{11}(s)=g_{11}(s) e^{-\tau_{11 n} s} \text {. }
$$

It can be seen from Figure 4(a) that $e^{-\tau_{11} s}$ is inserted into the channel of $U_{1}(s)$. Moreover, $g_{11}(s)$ is inserted into the channel of $Y_{1}(s)$ to substitute $G(s)$.

In Figure 4(b), we take model mismatches into consideration. Obviously, $D_{1}(s)$ consists of the external disturbance $D_{\text {exl }}(s)$ and the internal disturbance containing $D_{m 1}(s)$ resulting from model mismatching and $D_{c 1}(s)$ resulting from coupling, i.e.,

$$
D_{1}(s)=D_{\text {exl }}(s)+D_{m 1}(s)+D_{c 1}(s),
$$




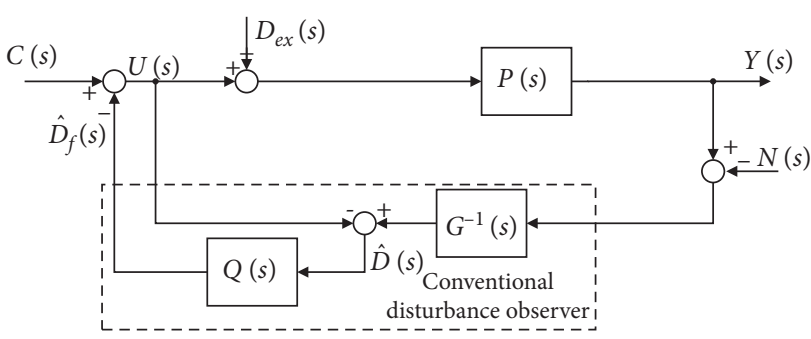

(a)

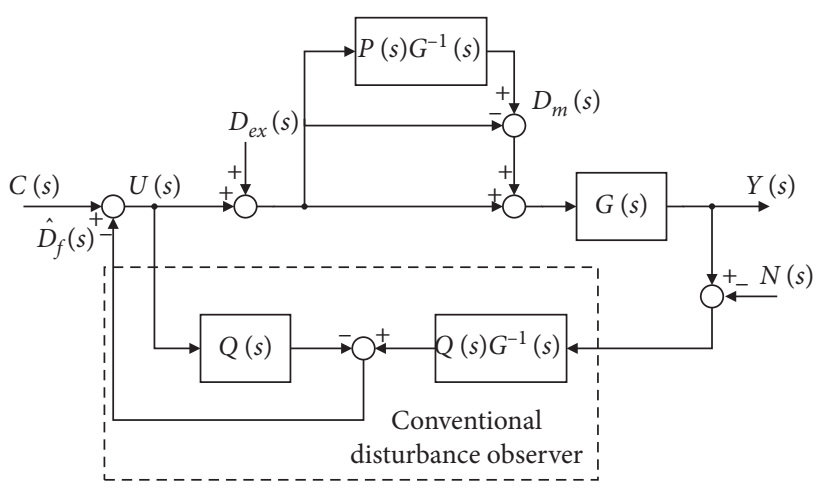

(b)

FIgURE 3: Block diagrams of conventional DO.

where $D_{m 1}(s)=\left[p_{11}(s) e^{-\tau_{11} s}-g_{11}(s) e^{-\tau_{11 n} s}\right] U_{1}(s), D_{c 1}(s)$ $=p_{12}(s) e^{-\tau_{12} s} U_{2}(s)$.

From Figure 4(b), one obtains

$$
Y_{1}(s)=g_{11}(s) e^{-\tau_{11 n} s} U_{1}(s)+D_{m 1}(s)+D_{\text {exl }}(s)+D_{c 1}(s) .
$$

Substituting (14) into (15) yields

$$
Y_{1}(s)=g_{11}(s) e^{-\tau_{11 n} s} U_{1}(s)+D_{1}(s)
$$

If there is no sensor noise, i.e., $N_{1}(s)=0$, it can be inferred from Figure 4(b) that

$$
\widehat{D}_{f 1}(s)=Q(s) g_{11}^{-1}(s) Y_{1}(s)-Q(s) e^{-\tau_{11 n} s} U_{1}(s) .
$$

Substituting (16) into (17) yields

$$
\widehat{D}_{f 1}(s)=Q(s) g_{11}^{-1}(s) D_{1}(s) \text {. }
$$

Define $\widetilde{D}(s)$ as the error between the real value and the estimated value of the lumped disturbance, i.e.,

$$
\widetilde{D}_{1}(s)=D_{1}(s)-g_{11}(s) e^{-\tau_{11 n} s} \widehat{D}_{f 1}(s) .
$$

Substituting (18) into (19), one obtains

$$
\widetilde{D}_{1}(s)=\left[1-Q(s) e^{-\tau_{11 n} s}\right] D_{1}(s) \text {. }
$$

According to the final-value theorem, one has

$$
\begin{aligned}
\widetilde{d}_{1}(\infty) & =\lim _{t \longrightarrow \infty} \widetilde{d}_{1}(t)=\lim _{s \longrightarrow 0} s \widetilde{D}_{1}(s) \\
& =\lim _{s \longrightarrow 0}\left[1-Q(s) e^{-\tau_{11 n} s}\right] \lim _{s \longrightarrow 0} s D_{1}(s) \\
& =\lim _{s \longrightarrow 0}\left[1-Q(s) e^{-\tau_{11 n} s}\right] \lim _{t \longrightarrow \infty} d_{1}(t) \\
& =\lim _{s \longrightarrow 0}\left[1-Q(s) e^{-\tau_{11 n} s}\right] d_{1}(\infty) .
\end{aligned}
$$

Obviously, if the steady-state gain of $Q(s)$ is 1 , one obtains from (21) that

$$
\tilde{d}_{1}(\infty)=0
$$

Here $Q(s)$ is a first-order low-pass filter with the steadystate gain of 1, which has the following form:

$$
Q(s)=\frac{1}{\lambda s+1} \text {. }
$$

Multiple DOs should be designed for the multi-inputmulti-output system. The time constants of the filters in DOs must be debugged to compensate for different types of disturbances [33].

\section{Simulations}

In this section, the three-input-three-output model is firstly introduced. Then, the schematic diagram of MPC-DO is illustrated. After that, simulation of tracking and anti-interference is given to verify the effectiveness of the proposed controller.

4.1. Model Description. As mentioned in Section 3.2, a twoinput-two-output model [11] is generally applied to describe the grinding process of the ball mill. The manipulated variables of the second-order system are fresh ore feed rate $u_{1}(t / h)$ and dilution water feed rate $u_{2}\left(\mathrm{~m}^{3} / \mathrm{h}\right)$, while the controlled variables are product particle size $y_{1}$ (\%-200 mesh) and circulating load $y_{2}(t / h)$, respectively. However, this type of model cannot describe the system precisely as it does not take the factor of mill feed water rate into consideration. According to the analysis in Section 2, the mill feed water rate ought to be another manipulated factor because it affects next series of operations. Moreover, on the basis of process description, mill solid concentration must be controlled within a reasonable range to avoid increasing the workload of subsequent operations. Therefore, it is another significant controlled variable.

In this paper, a three-input-three-output system is proposed to describe the grinding process of the ball mill. The manipulated variables are fresh ore feed rate $u_{1}(t / h)$, dilution water feed rate $u_{2}\left(\mathrm{~m}^{3} / \mathrm{h}\right)$, and mill feed water feed rate $u_{3}(\%$ solids), while the controlled variables are product particle size $y_{1}$ (\%-200 mesh), circulating load $y_{2}(t / h)$, and mill solid concentration $y_{3}$ (\% solids), respectively. The system is illustrated in Figure 5. Considering the standards of production, the scope of $y_{1}$ is $65 \%-75 \%$, the scope of $y_{2}$ is $120 \mathrm{t} /$ $h-180 \mathrm{t} / \mathrm{h}$, and the scope of $y_{3}$ is $40 \%$ solids $\sim 60 \%$ solids. 

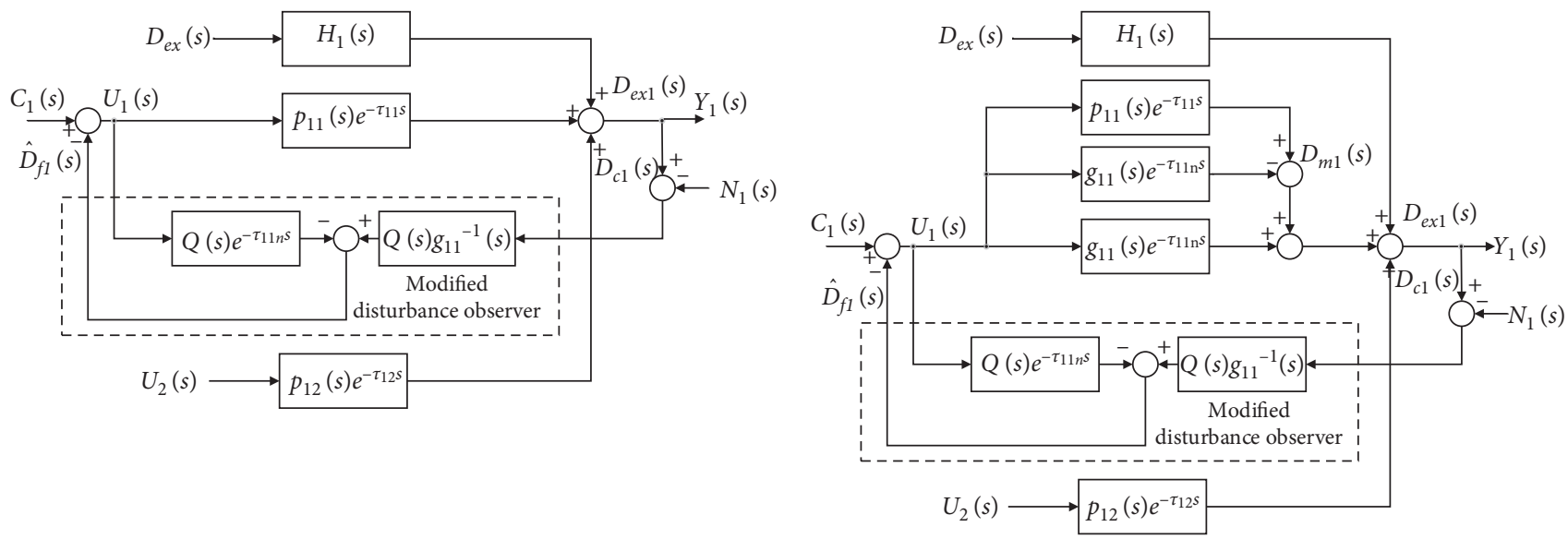

(a)

(b)

FIgURE 4: Block diagrams of modified DO.

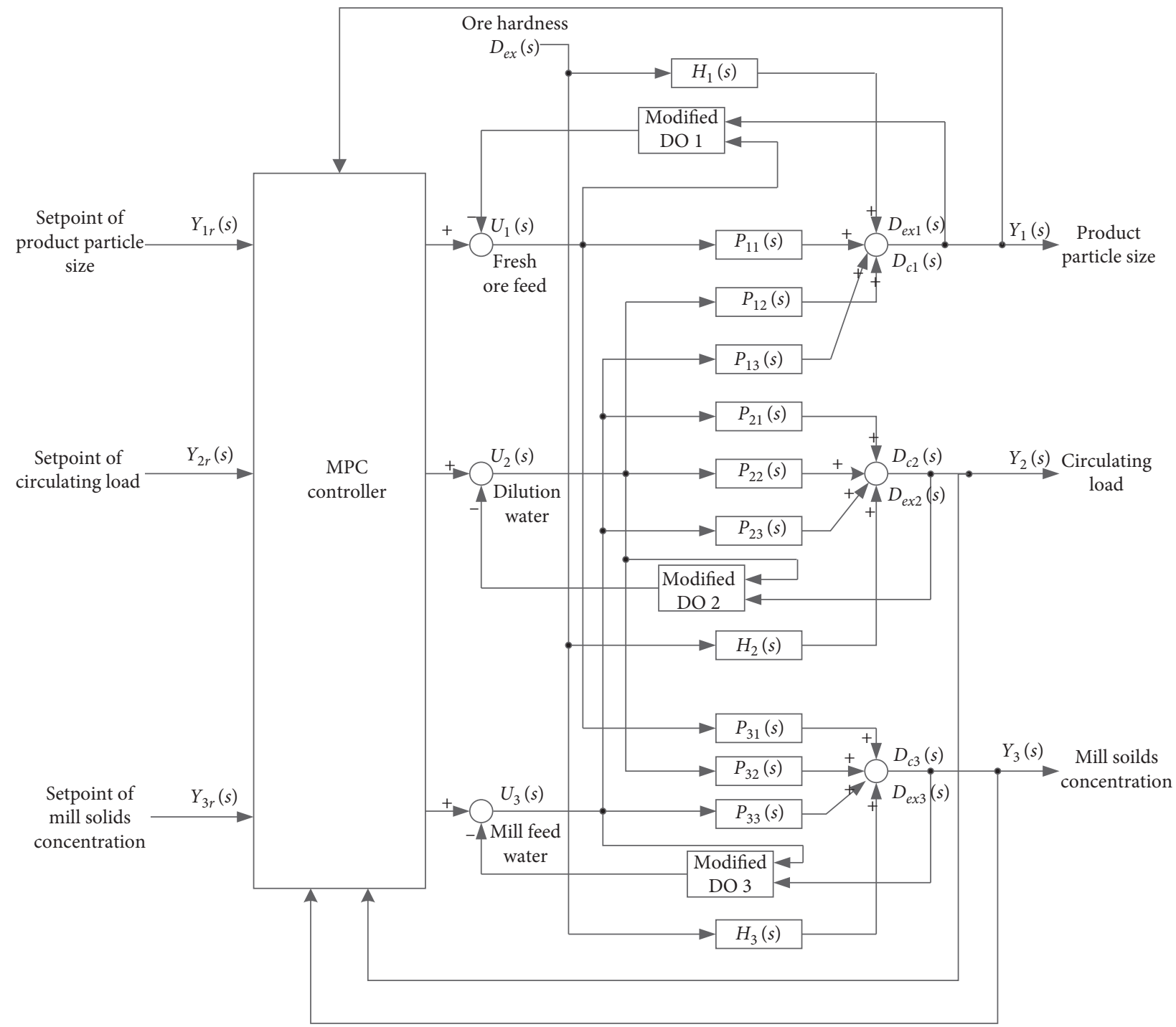

FIGURE 5: Schematic diagram of MPC-DO applied in the grinding process of ball mill. 
TABLE 1: The parameters of the simulation.

\begin{tabular}{lccc}
\hline Setpoint of $u_{1}$ & Setpoint of $u_{2}$ & Setpoint of $u_{3}$ & Sampling time (s) \\
\hline $70 \%-200$ mesh & $150 \mathrm{t} / \mathrm{h}$ & $50 \%$ solids & 0.1 \\
$\lambda_{1}$ of $\mathrm{DO}_{1}$ & $\lambda_{2}$ of $\mathrm{DO}_{2}$ & $\lambda_{3}$ of $\mathrm{DO}_{3}$ & - \\
1 & 0.8 & 0.7 & - \\
\hline
\end{tabular}

Assume that the real grinding process of ball mill holds where the following form:

$$
\left[\begin{array}{l}
Y_{1}(s) \\
Y_{2}(s) \\
Y_{3}(s)
\end{array}\right]=\left[\begin{array}{lll}
G_{11}(s) & G_{12}(s) & G_{13}(s) \\
G_{21}(s) & G_{22}(s) & G_{23}(s) \\
G_{31}(s) & G_{32}(s) & G_{33}(s)
\end{array}\right]\left[\begin{array}{c}
U_{1}(s) \\
U_{2}(s) \\
U_{3}(s)
\end{array}\right]
$$

$$
\begin{aligned}
& G_{11}(s)=g_{11}(s) e^{-\tau_{11 n} s}=\frac{-2.75 e^{-38 s}}{89 s+1}, \\
& G_{12}(s)=g_{12}(s) e^{-\tau_{12 n} s}=\frac{1.85 e^{-56 s}\left(1-0.99 e^{-260 s}\right)}{(138 s+1)(205 s+1)}, \\
& G_{13}(s)=g_{13}(s) e^{-\tau_{13 n} s}=\frac{8.2 e^{-8 s}\left(1-0.97 e^{-220 s}\right)}{(19 s+1)(46 s+1)}, \\
& G_{21}(s)=g_{21}(s)=\frac{1.54}{127 s+1}, \\
& G_{22}(s)=g_{22}(s)=\frac{-3.23}{125 s+1}, \\
& G_{23}(s)=g_{23}(s) e^{-\tau_{23 n} s}=\frac{1.54 e^{-84 s}}{(83 s+1)(187 s+1)}, \\
& G_{31}(s)=g_{31}(s) e^{-\tau_{31 n} s}=\frac{1.08 e^{-48 s}}{127 s+1}, \\
& G_{32}(s)=g_{32}(s) e^{-\tau_{32 n} s}=\frac{0.34 e^{-94 s}}{(127 s+1)(264 s+1)}, \\
& g_{33}(s) e^{-\tau_{33 n} s}=\frac{3.46 e^{-7 s}}{174 s+1} .
\end{aligned}
$$

It must be noted that the time constants are expressed in seconds. The establishment of the model is based on process testing. Specifically, a step disturbance is applied to one of the manipulated variables near the equilibrium point in turn to observe the dynamic changes of the three controlled variables. By observing the dynamic changes, the change curves can be obtained, and the transfer function models can be obtained by curve fitting. The transfer function consists of a minimum-phase part and a time delay part. The model holds the following form:

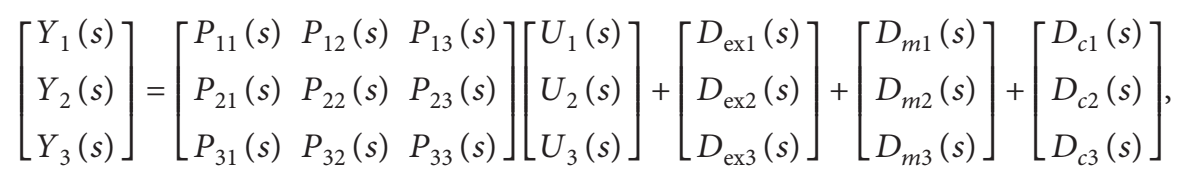




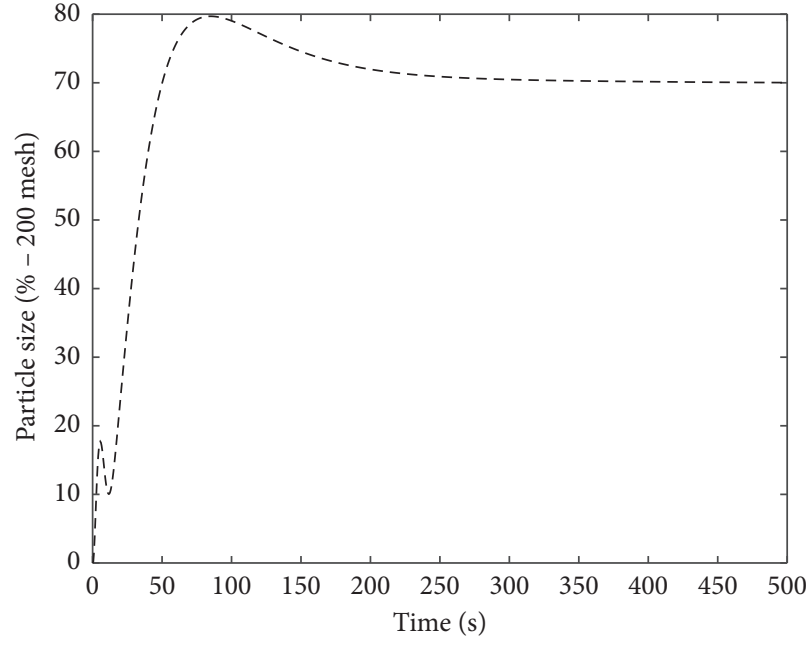

(a)

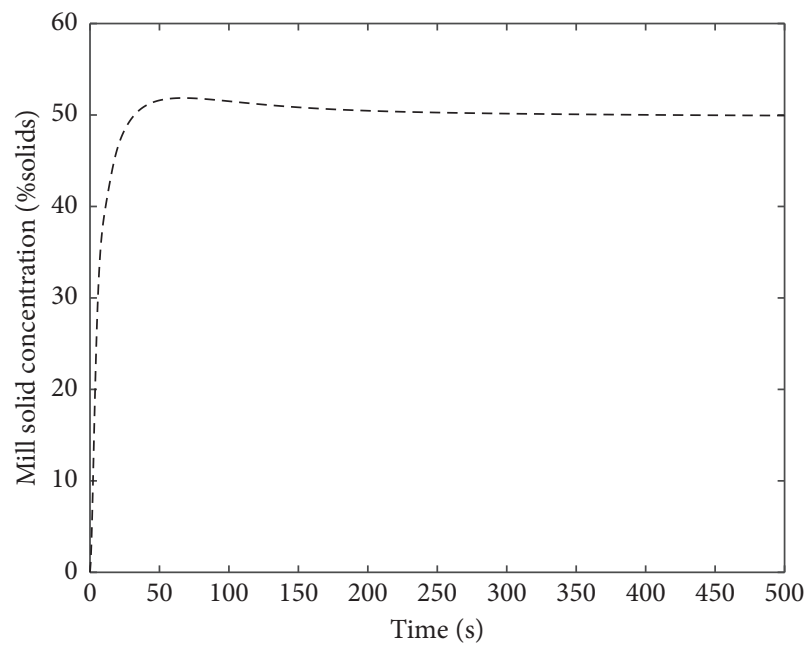

(c)

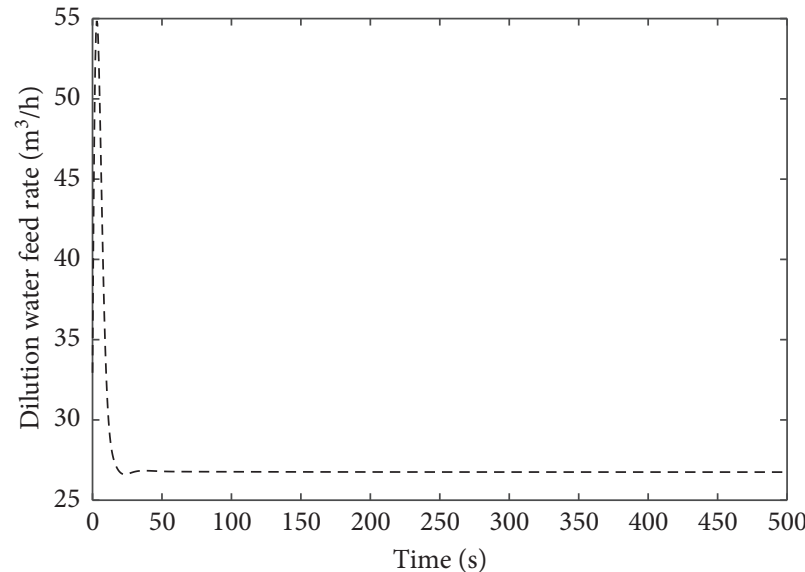

(e)

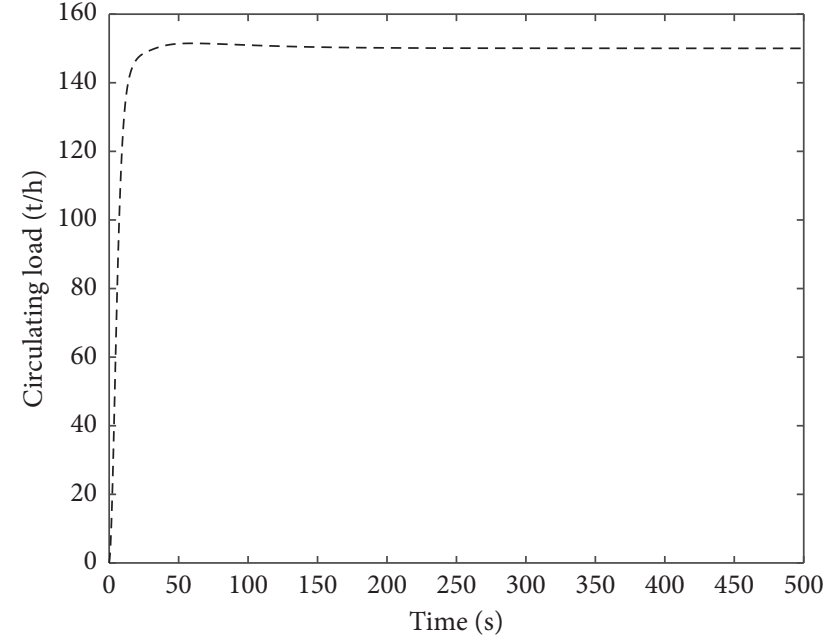

(b)

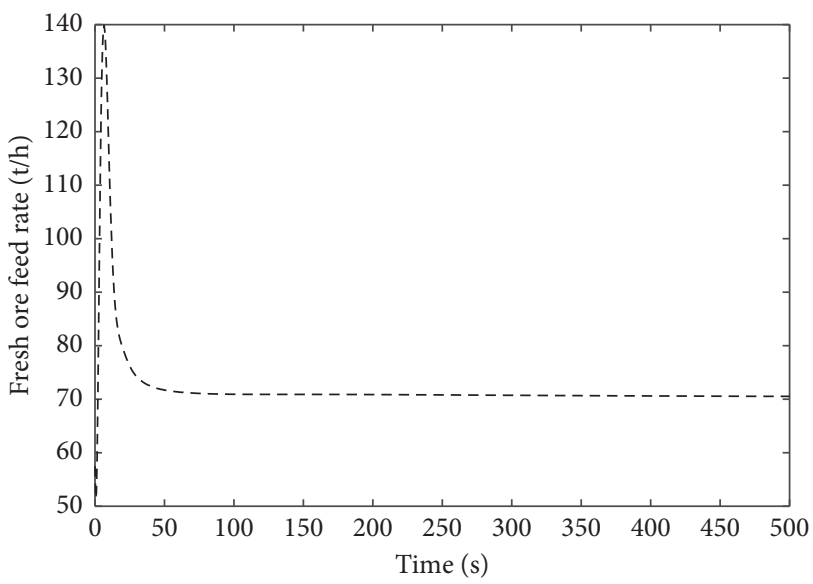

(d)

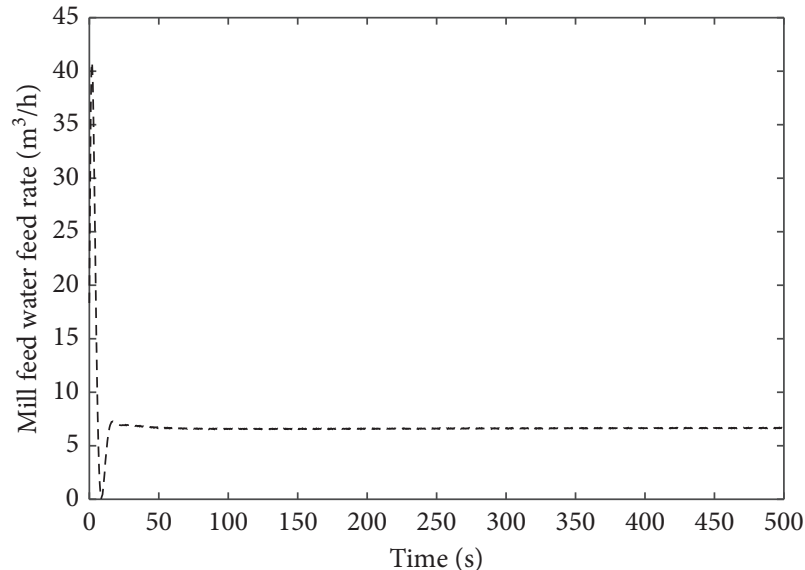

(f)

FiguRE 6: Response curves of controlled variables and manipulated variables for tracking setpoint: (a) product particle size; (b) circulating load; (c) mill solid concentration; (d) fresh ore feed rate; (e) dilution water feed rate; (f) mill feed water feed rate. 


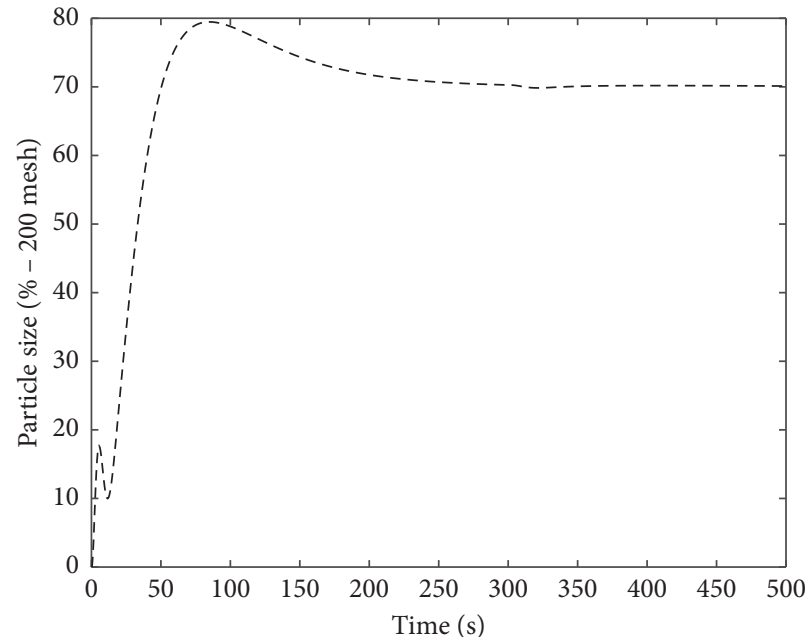

(a)

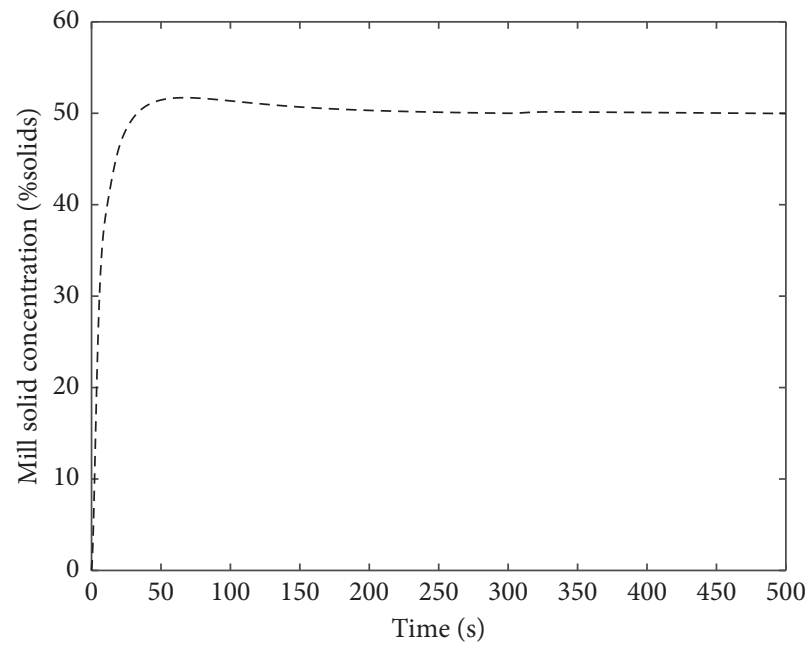

(c)

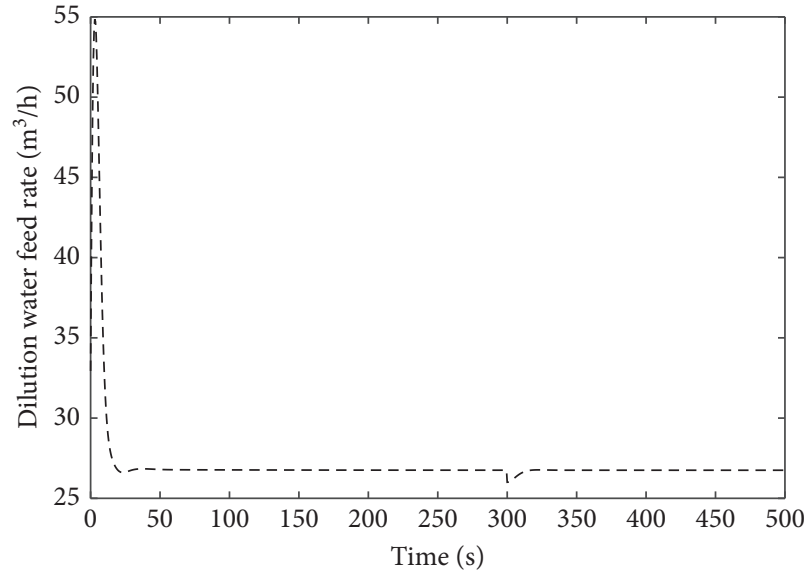

(e)

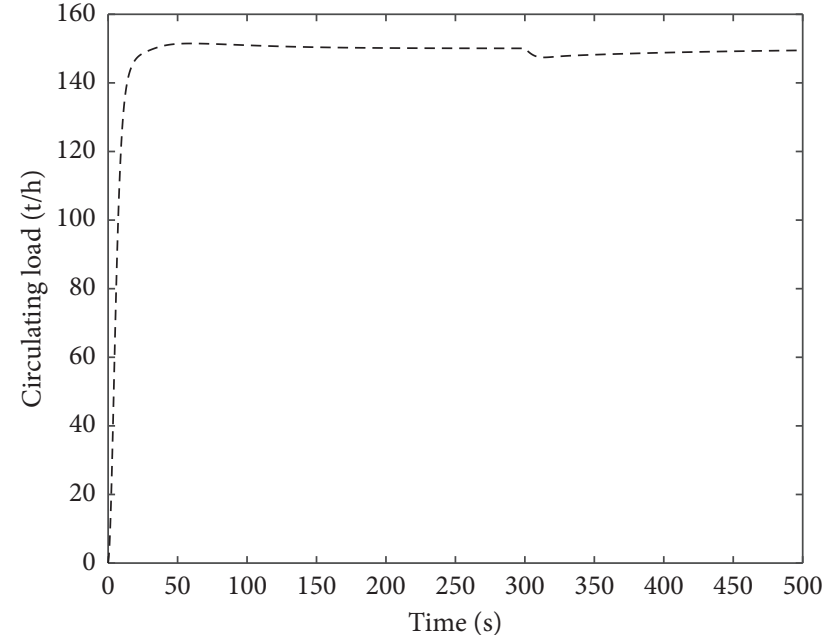

(b)

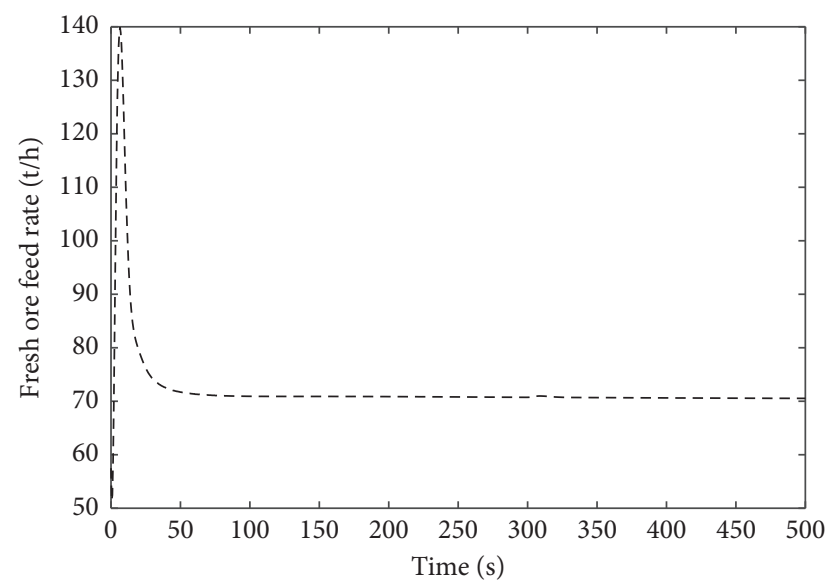

(d)

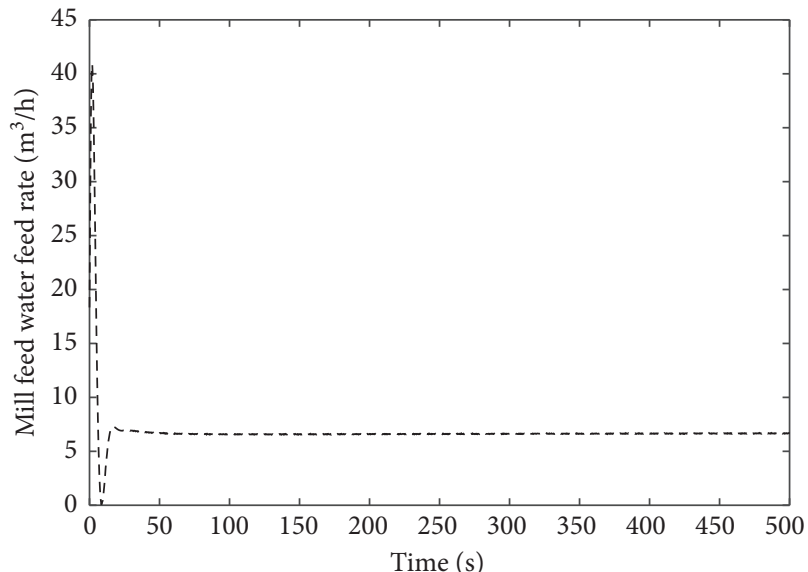

(f)

FIgURE 7: Response curves of controlled variables and manipulated variables in the presence of strong external disturbance: (a) product particle size; (b) circulating load; (c) mill solid concentration; (d) fresh ore feed rate; (e) dilution water feed rate; (f) mill feed water feed rate. 


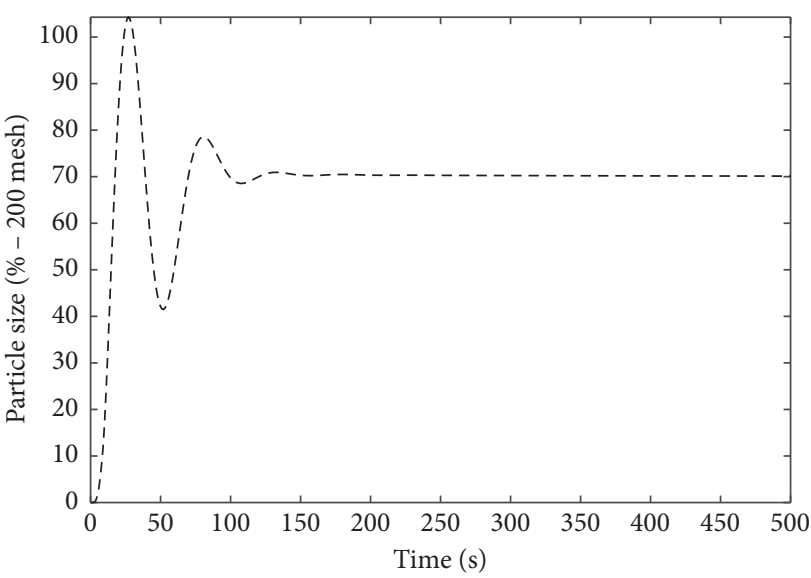

(a)

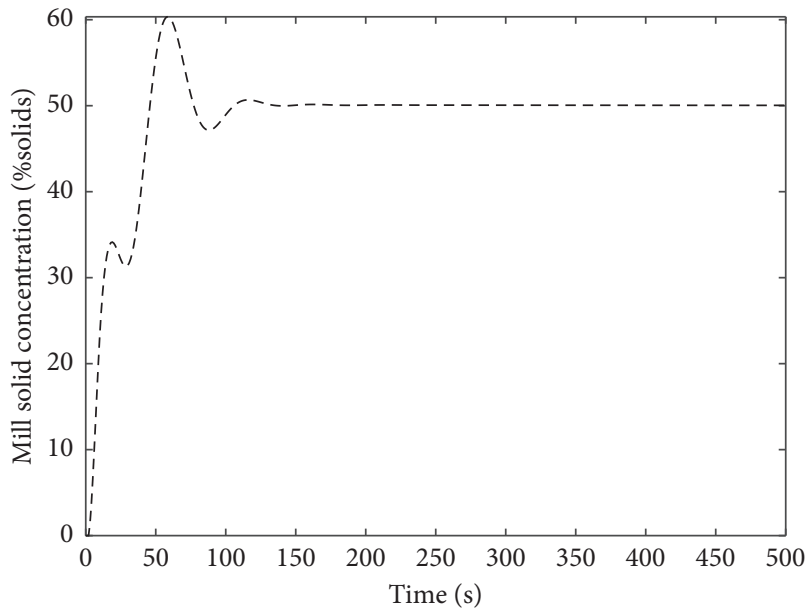

(c)

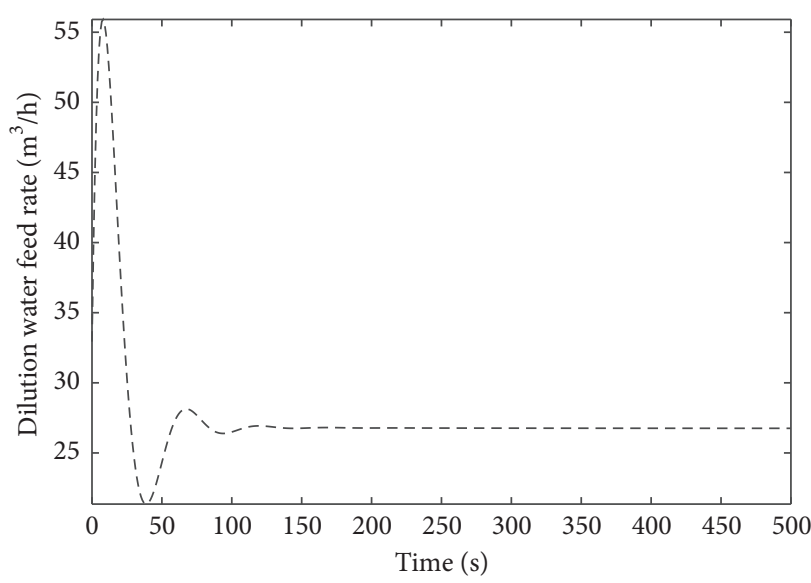

(e)

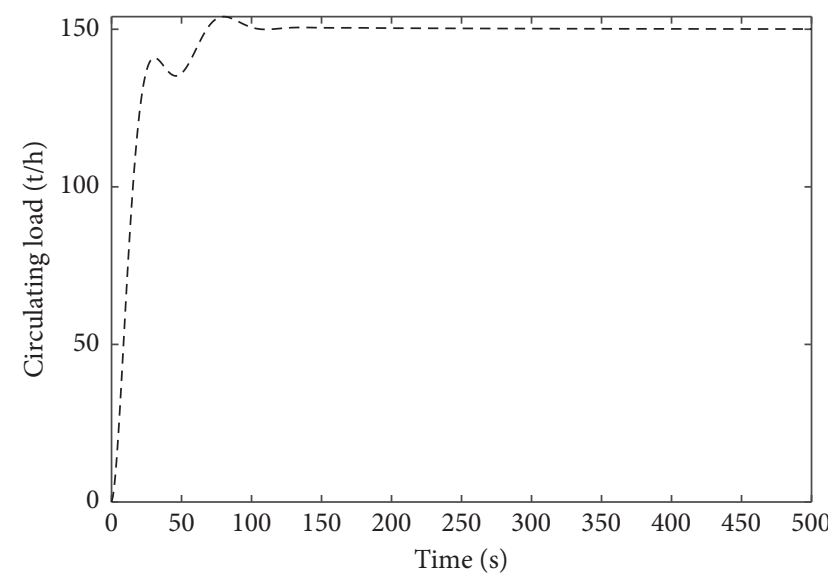

(b)

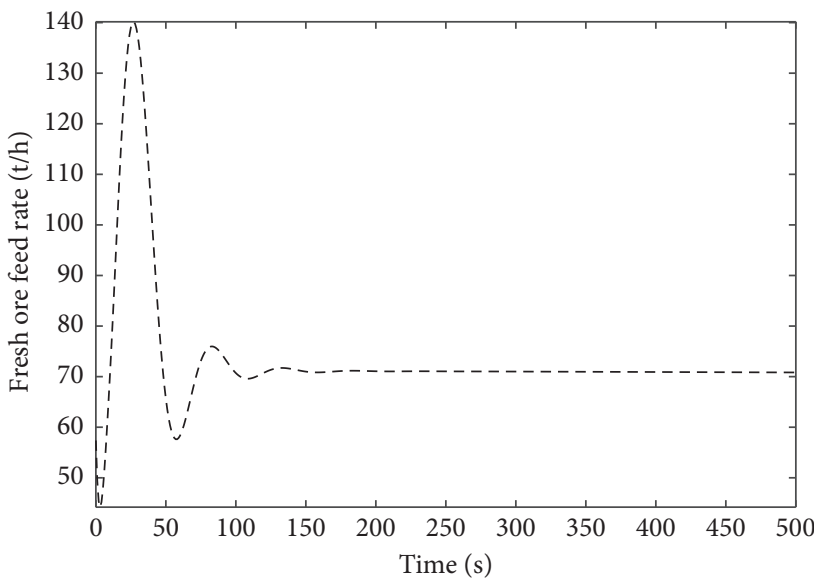

(d)

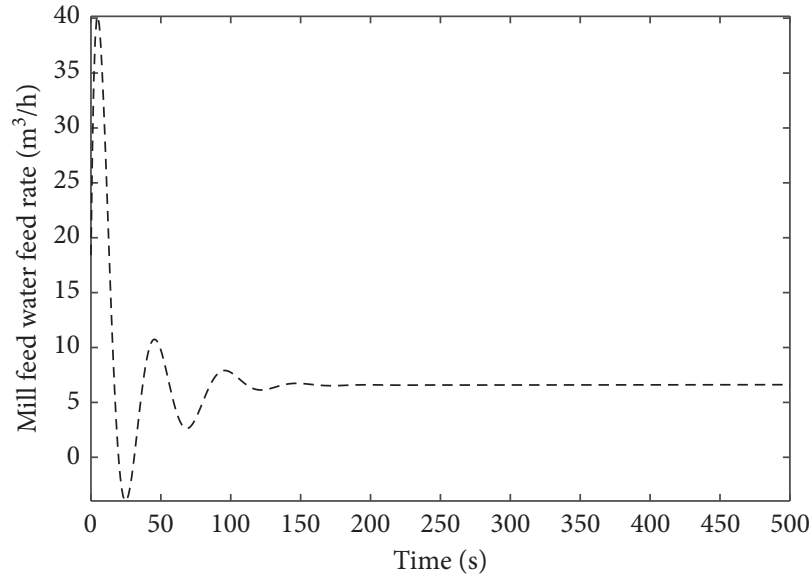

(f)

FIGURE 8: Response curves of controlled variables and manipulated variables for tracking setpoint: (a) product particle size; (b) circulating load; (c) mill solid concentration; (d) fresh ore feed rate; (e) dilution water feed rate; (f) mill feed water feed rate.

TABle 2: The performance indexes of $y_{1}$.

\begin{tabular}{lccc}
\hline Controller & Overshoot $(\%)$ & Peak time $(\mathrm{s})$ & Steady-state time $(\mathrm{s})$ \\
\hline MPC-DO & 13.52 & 84 & 335 \\
MPC & 45 & 104 & 320 \\
\hline
\end{tabular}


where

$$
\begin{aligned}
& P_{11}(s)=p_{11}(s) e^{-\tau_{11} s}=\frac{-2.85 e^{-45 s}}{95 s+1}, \\
& P_{12}(s)=p_{12}(s) e^{-\tau_{12} s}=\frac{1.87 e^{-60 s}\left(1-1.09 e^{-260 s}\right)}{(140 s+1)(210 s+1)}, \\
& P_{13}(s)=p_{13}(s) e^{-\tau_{13} s}=\frac{8.32 e^{-10 s}\left(1-1.07 e^{-220 s}\right)}{(21 s+1)(47 s+1)}, \\
& P_{21}(s)=p_{21}(s)=\frac{1.57}{130 s+1}, \\
& P_{22}(s)=p_{22}(s)=\frac{-3.46}{130 s+1}, \\
& P_{23}(s)=p_{23}(s) e^{-\tau_{23} s}=\frac{1.55 e^{-90 s}}{(85 s+1)(190 s+1)}, \\
& P_{31}(s)=p_{31}(s) e^{-\tau_{31} s}=\frac{1.14 e^{-50 s}}{140 s+1}, \\
& P_{32}(s)=p_{32}(s) e^{-\tau_{32} s}=\frac{0.38 e^{-100 s}}{(130 s+1)(270 s+1)}, \\
& P_{33}(s)=p_{33}(s) e^{-\tau_{33} s}=\frac{3.59 e^{-10 s}}{180 s+1}, \\
& D_{e x 1}(s)=H_{1}(s) D_{e x}(s)=\frac{-6.4 e^{-0.52 s}}{4.8 s+1} D_{e x}(s), \\
& D_{e x 2}(s)=H_{2}(s) D_{e x}(s)=\frac{-8.6 e^{-0.58 s}}{5.2 s+1} D_{e x}(s), \\
& D_{e x 3}(s)=H_{3}(s) D_{e x}(s)=\frac{7.5 e^{-0.46 s}}{5.3 s+1} D_{e x}(s), \\
& D_{m 1}(s)=\left[p_{11}(s) e^{-\tau_{11} s}-g_{11}(s) e^{-\tau_{11 n} s}\right] U_{1}(s), \\
& D_{m 2}(s)=\left[p_{22}(s) e^{-\tau_{22} s}-g_{22}(s) e^{-\tau_{22 n} s}\right] U_{2}(s), \\
& D_{m 3}(s)=\left[p_{33}(s) e^{-\tau_{33} s}-g_{33}(s) e^{-\tau_{33 n} s}\right] U_{3}(s), \\
& D_{c 1}(s)=P_{12}(s) U_{2}(s)+P_{13}(s) U_{3}(s), \\
& D_{c 2}(s)=P_{22}(s) U_{2}(s)+P_{23}(s) U_{3}(s), \\
& D_{c 3}(s)=P_{32}(s) U_{2}(s)+P_{33}(s) U_{3}(s) .
\end{aligned}
$$

4.2. Simulation of Tracking and Anti-Interference. The parameters set in the simulation are listed in Table 1.

Firstly, response curves of controlled variables and manipulated variables for tracking setpoint are listed as follows. The setpoints of $u_{1}, u_{2}$, and $u_{3}$ are selected as $70 \%$ $200 \mathrm{mesh}, 150 \mathrm{t} / \mathrm{h}$, and $50 \%$ solids, respectively. The whole period is selected as 500 seconds.
TABle 3: The performance indexes of $y_{2}$.

\begin{tabular}{lccc}
\hline Controller & Overshoot (\%) & Peak time $(\mathrm{s})$ & Steady-state time $(\mathrm{s})$ \\
\hline MPC-DO & 1 & 54 & 208 \\
MPC & 2.67 & 79 & 262 \\
\hline
\end{tabular}

TABle 4: The performance indexes of $y_{3}$.

\begin{tabular}{lccc}
\hline Controller & Overshoot (\%) & Peak time (s) & Steady-state time (s) \\
\hline MPC-DO & 3.4 & 51.7 & 298.5 \\
MPC & 20.66 & 58 & 228
\end{tabular}

Figures 6(a)-6(c) illustrate the controlled variables during the process of ball mill grinding circuits. Furthermore, Figures 6(d)-6(f) show the variations of the manipulated variables.

After that, a step signal is imposed as a strong external disturbance to verify the performance of anti-interference under the compound control strategy. The results are shown in Figure 7.

It can be seen from simulation that the system stabilizes after $25 \mathrm{~s}$ under the influence of manipulated variables. The composite control strategy based on MPC-DO shows a perfect anti-disturbance performance, achieving the goal of controller design.

To make a comparison between the proposed controller and MPC controller, the MPC controller is applied to the three-input-three-output system. The tracking performance is shown in Figure 8.

The performance indexes, including overshoot, peak time, and steady-state time, are employed here to estimate the control performance of setpoint tracking. Comparisons about the performance of MPC-DO controller and MPC controller are listed in Tables 2-4.

From the performance index analysis above, it can be concluded that the MPC controller has the disadvantage of high overshoot when strong disturbances exist, especially product particle size $y_{1}$, which reaches $45 \%$. It is likely to bring negative impact to the production process. With the assistance of MPC-DO controller, the problem of excessive overshoot is solved. It indicates that the proposed MPC-DO controller has excellent performance.

\section{Conclusion}

In GCP, complicated disturbances have negative effects on the ball mill grinding system. A three-input-three-output model is introduced in the paper to deal with the problem that traditional two-input-two-output model cannot describe the characteristics of the system precisely. Then, a compound control strategy including a feedback regulation component based on MPC and a feed-forward compensation component based on DO is proposed in order to improve the performance of anti-disturbance. Except for external disturbances, internal disturbances resulting from model mismatches are viewed as a part of the lumped disturbance. Simulation results demonstrate that the composite control strategy based on MPC-DO has achieved 
remarkable performance when applied to a three-input-three-output model of grinding process. In the follow-up research, advanced control methods ought to be studied further to meet the requirements of industrial production. Furthermore, the influence of other factors, such as the level of pump sump, the running speed of pump, and so on, ought to be studied to extend the model of the system to higher dimensions.

\section{Data Availability}

No data were used to support this study.

\section{Conflicts of Interest}

The authors declare that they have no conflicts of interest.

\section{Acknowledgments}

This study was funded by the Open Foundation of State Key Laboratory of Process Automation in Mining \& Metallurgy (BGRIMN-KZSKL-2020-11).

\section{References}

[1] L. Lv, Z. Deng, T. Liu, Z. Li, and W. Liu, "Intelligent technology in grinding process driven by data: a review," Journal of Manufacturing Processes, vol. 58, pp. 1039-1051, 2020.

[2] X. Wang, Y. Wang, C. Yang, D. Xu, and W. Gui, "Hybrid modeling of an industrial grinding-classification process," Powder Technology, vol. 279, pp. 75-85, 2015.

[3] X.-S. Chen, Q. Li, and S.-M. Fei, "Supervisory expert control for ball mill grinding circuits," Expert Systems with Applications, vol. 34, no. 3, pp. 1877-1885, 2008.

[4] V. Chipakwe, P. Semsari, T. Karlkvist, J. Rosenkranz, and S. C. Chelgani, "A critical review on the mechanisms of chemical additives used in grinding and their effects on the downstream processes," Journal of Materials Research and Technology, vol. 9, no. 4, pp. 8148-8162, 2020.

[5] J. Yu, Y. Qin, P. Gao, Y. Han, and Y. Li, "An innovative approach for determining the grinding media system of ball mill based on grinding kinetics and linear superposition principle," Powder Technology, vol. 378, pp. 172-181, 2021.

[6] A. Pomerleau, D. Hodouin, A. Desbiens, and É. Gagnon, “A survey of grinding circuit control methods: from decentralized PID controllers to multivariable predictive controllers," Powder Technology, vol. 108, no. 2-3, pp. 103-115, 2000.

[7] A. J. Niemi, L. Tian, and R. Ylinen, "Model predictive control for grinding systems," Control Engineering Practice, vol. 5, no. 2, pp. 271-278, 1997.

[8] M. Ramasamy, S. S. Narayanan, and C. D. P. Rao, "Control of ball mill grinding circuit using model predictive control scheme," Journal of Process Control, vol. 15, no. 3, pp. 273-283, 2005.

[9] X.-S. Chen, J.-Y. Zhai, S.-H. Li, and Q. Li, "Application of model predictive control in ball mill grinding circuit," Minerals Engineering, vol. 20, no. 11, pp. 1099-1108, 2007.

[10] X.-S. Chen, Q. Li, and S.-M. Fei, "Constrained model predictive control in ball mill grinding process," Powder Technology, vol. 186, no. 1, pp. 31-39, 2008.

[11] J. Yang, S. Li, X. Chen, and Q. Li, "Disturbance rejection of ball mill grinding circuits using DOB and MPC," Powder Technology, vol. 198, no. 2, pp. 219-228, 2010.
[12] A. Cortinovis, H. J. Ferreau, D. Lewandowski, and M. Mercangöz, "Experimental evaluation of MPC-based antisurge and process control for electric driven centrifugal gas compressors," Journal of Process Control, vol. 34, pp. 13-25, 2015.

[13] K. Najim, D. Hodouin, and A. Desbiens, "Adaptive control: state of the art and an application to a grinding process," Powder Technology, vol. 82, no. 1, pp. 59-68, 1995.

[14] L. P. Xin, B. Yu, and L. Zhao, "Adaptive fuzzy backstepping control for a two continuous stirred tank reactors process based on dynamic surface control approach," Applied Mathematics and Computation, vol. 377, pp. 125-138, 2020.

[15] J. J. Govindhasamy, S. F. McLoone, G. W. Irwin, J. J. French, and R. P. Doyle, "Neural modelling, control and optimisation of an industrial grinding process," Control Engineering Practice, vol. 13, no. 10, pp. 1243-1258, 2005.

[16] O. Galán, G. W. Barton, and J. A. Romagnoli, "Robust control of a SAG mill," Powder Technology, vol. 124, no. 3, pp. 264-271, 2002.

[17] E. M. Arruda, A. P. de Paiva, L. C. Brandão, and J. R. Ferreira, "Robust optimisation of surface roughness of AISI H13 hardened steel in the finishing milling using ball nose end mills," Precision Engineering, vol. 60, pp. 194-214, 2019.

[18] H. Fujii, A. Iwanade, S. Kawada, and H. Kitaguchi, "The reduction of optimal heat treatment temperature and critical current density enhancement of ex situ processed MgB2 tapes using ball milled filling powder," Cryogenics, vol. 89, pp. 76-84, 2018.

[19] X.-S. Chen, S.-H. Li, J.-Y. Zhai, and Q. Li, "Expert system based adaptive dynamic matrix control for ball mill grinding circuit," Expert Systems with Applications, vol. 36, no. 1, pp. 716-723, 2009.

[20] J. Richalet, A. Rault, J. L. Testud, and J. Papon, "Model predictive heuristic control," Automatica, vol. 14, no. 5, pp. 413-428, 1978.

[21] R. Rouhani and R. K. Mehra, "Model algorithmic control (MAC); basic theoretical properties," Automatica, vol. 18, no. 4, pp. 401-414, 1982.

[22] X. S. Chen, J. Yang, and S. H. Li, "Disturbance observer based multivariable control of ball mill grinding circuits," Journal of Process Control, vol. 19, pp. 1205-1213, 2019.

[23] K. Ohishi, M. Nakao, K. Ohnishi, and K. Miyachi, "Microprocessor-controlled DC motor for load-insensitive position servo system," IEEE Transactions on Industrial Electronics, vol. 34, no. 1, pp. 44-49, 1987.

[24] S. Katsura, Y. Matsumoto, and K. Ohnishi, "Modeling of force sensing and validation of disturbance observer for force control," IEEE Transactions on Industrial Electronics, vol. 54, no. 1, pp. 530-538, 2007.

[25] S. Ueki, T. Mouri, and H. Kawasaki, "Nonlinear disturbance observer for object grasping/manipulation by multi-fingered robot hand," IFAC-PapersOnLine, vol. 50, no. 1, pp. 12704-12709, 2017.

[26] J. Ishikawa and M. Tomizuka, "A novel add-on compensator for cancellation of pivot nonlinearities in hard disk drives," IEEE Transactions on Magnetics, vol. 34, no. 4, pp. 1895-1897, 1998.

[27] Y. Luo, T. Zhang, B. Lee, C. Kang, and Y. Chen, "Disturbance observer design with Bode's ideal cut-off filter in hard-discdrive servo system," Mechatronics, vol. 23, no. 7, pp. 856-862, 2013.

[28] H. Pan, W. Sun, H. Gao, and X. Jing, "Disturbance observerbased adaptive tracking control with actuator saturation and 
its application," IEEE Transactions on Automation Science and Engineering, vol. 13, no. 2, pp. 1-8, 2016.

[29] D. Hodouin, S.-L. Jämsä-Jounela, M. T. Carvalho, and L. Bergh, "State of the art and challenges in mineral processing control," Control Engineering Practice, vol. 9, no. 9, pp. 995-1005, 2001.

[30] D. Li, H. Cao, X. Zhang, X. Chen, and R. Yan, "Model predictive control based active chatter control in milling process," Mechanical Systems and Signal Processing, vol. 128, pp. 266-281, 2019.

[31] W. R. Wang, S. X. Pan, and F. Wang, "A comparison study of two disturbance rejection control strategies for hydraulic position servo systems," in Procceedings of the 30th Annual Conference of the IEEE Industrial Electronics Society, 2004 (IECON 2004), pp. 1993-1996, Busan, Republic of Korea, November 2004.

[32] H. D. Zhu, G. H. Zhang, and H. H. Shao, "Control of the process with inverse response and dead-time based on disturbance observer," in Procceedings of the 2005 American Control Conference, pp. 4826-4831, Portland, OR, USA, June 2005.

[33] T. Umeno and Y. Hori, "Robust speed control of DC servomotors using modern two degrees-of-freedom controller design," IEEE Transactions on Industrial Electronics, vol. 38, no. 5, pp. 363-368, 1991. 